\title{
OPEN Author Correction: Self-organized intestinal epithelial monolayers in crypt and villus-like domains show effective barrier function
}

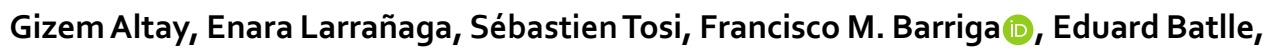 \\ Vanesa Fernández-Majada \& Elena Martínez
}

Correction to: Scientific Reports https://doi.org/10.1038/s41598-019-46497-x, published online 12 July 2019

In the original version of this Article, Eduard Batlle was incorrectly affiliated with 'Colorectal Cancer Laboratory, Institute for Research in Biomedicine (IRB Barcelona), The Barcelona Institute of Science and Technology (BIST), Baldiri Reixac 10-12, Barcelona, 08028, Spain'. In addition, two affiliations for Eduard Batlle were omitted. The correct affiliations are listed below:

Institute for Research in Biomedicine (IRB Barcelona), The Barcelona Institute of Science and Technology (BIST), Baldiri Reixac 10-12, Barcelona 08028, Spain

Centro de Investigación Biomédica en Red de Cáncer (CIBERONC), Barcelona, Spain

ICREA, Passeig Lluís Companys 23, 08010 Barcelona, Spain

This error has now been corrected in the PDF and HTML versions of the Article.

(c) (i) Open Access This article is licensed under a Creative Commons Attribution 4.0 International License, which permits use, sharing, adaptation, distribution and reproduction in any medium or format, as long as you give appropriate credit to the original author(s) and the source, provide a link to the Creative Commons license, and indicate if changes were made. The images or other third party material in this article are included in the article's Creative Commons license, unless indicated otherwise in a credit line to the material. If material is not included in the article's Creative Commons license and your intended use is not permitted by statutory regulation or exceeds the permitted use, you will need to obtain permission directly from the copyright holder. To view a copy of this license, visit http://creativecommons.org/licenses/by/4.0/.

(C) The Author(s) 2019 